\title{
Business fluctuations and bankruptcy avalanches in an evolving network economy
}

\author{
Domenico Delli Gatti • Mauro Gallegati • \\ Bruce C. Greenwald • Alberto Russo • \\ Joseph E. Stiglitz
}

Received: 30 September 2008 / Accepted: 13 May 2009 / Published online: 29 May 2009

(C) Springer-Verlag 2009

\begin{abstract}
We analyze the properties of a three-sector network economy characterized by credit relationships connecting downstream and upstream firms (inside credit) and credit relationships connecting firms and banks (outside credit). The network topology changes over time due to an endogenous process of partner selection (the preferred-partner choice rule). The output of simulations shows that a business cycle at the macroeconomic level can develop as a consequence of the complex interaction of the heterogeneous financial conditions of the agents involved. In this paper we focus on the emergence of bankruptcy crises: the bankruptcy of one agent can bring about the bankruptcy of one or more other agents in a snowball effect of more or less large size, depending on the network structure and the incidence of non-performing loans on balance sheets of agents involved.
\end{abstract}

Keywords Business fluctuations - Credit interlinkages · Network topology · Bankruptcy chain

D. Delli Gatti

Istituto di Teoria Economica, Università Cattolica, Largo Gemelli1, 20123 Milan, Italy

M. Gallegati · A. Russo $(\varangle)$

Dipartimento di Economia, Facoltà di Economia "Giorgio Fuà",

Università Politecnica delle Marche, Piazzale Martelli 8, 60121 Ancona, Italy

e-mail: albrusso@univpm.it

B. C. Greenwald

Columbia University, 611 Uris Hall, New York, NY 10027, USA

J. E. Stiglitz

Uris Hall, Columbia University, 3022 Broadway, New York, NY 10027, USA

J. E. Stiglitz

National Bureau of Economic Research (NBER), Cambridge, USA 


\section{JEL Classification $\quad \mathrm{C} 63 \cdot \mathrm{D} 85 \cdot \mathrm{E} 32$}

\section{Introduction}

In this paper we study the properties of a credit-network economy in which a multitude of heterogeneous agents interact giving rise to complex patterns of productive and credit relationships. The amplitude of business fluctuations is related to the network topology emerging from an endogenous process of partner selection. In particular, the evolution of the credit network depends on a preferred-partner choice rule according to which each agent selects the best partner in a limited set of observable partners due to imperfect information.

In this framework, it is straightforward to think of agents as nodes and of debt contracts as links in a credit network. Direct interaction-exemplified by debt contracts-is the raison d'etre of the network. Indirect interaction, i.e. interaction through "prices"-may still occur but does not necessarily lead to an equilibrium outcome, because decentralized decision making is not governed by a benevolent auctioneer, a pure figment of fantasy which we will get rid of in modelling the network. ${ }^{1}$

It is also straightforward to think of agents as intrinsically heterogeneous. Different characteristics such as technological, informational and financial endowments, preferences or expectations - to name just a few-can account for the role of lenders or borrowers that agents can assume.

Central to this picture is information, not only about the status of the parties in a credit relationship but also about the incentive structures that they face. The lender has to assess the risk involved in extending credit to a specified borrower and his ability and willingness to fulfill debt obligations. But information is asymmetric so that such an assessment is at best incomplete: all the issues crucial to modelling borrowers' and lenders' behaviour in an asymmetric information context are relevant also in designing the network of credit relationships. In this context, a simple and easily available indirect sign of the borrowers' creditworthiness is a measure of their financial soundness captured, for instance, by net worth.

In a credit relationship, a borrower may not be able to fulfill debt commitments, either by misfortune or mismanagement. The bankruptcy of a borrower is irrelevant if, so to speak, the agent is an "island". In a networked economy, bankruptcy will not be an isolated and therefore insignificant phenomenon. The bankruptcy of one agent can bring about the bankruptcy of one or more other agents in a snowball effect of more or less large size. In other words, in a credit network we can observe avalanches of bankruptcies.

Building upon ideas expounded first in Stiglitz and Greenwald (2003, Chapter 7), in Delli Gatti et al. (2006) we have modelled a credit network consisting of households, firms and banks. Agents are linked by inside credit (i.e. credit relationships

\footnotetext{
${ }^{1}$ Recent books by Jackson (2008), Vega-Redondo (2007) and Goyal (2007) describe the frontier of the research on economic networks. A growing literature has recently developed on the network analysis of the interbank market; see, for instance, Allen and Gale (200); Freixas et al. (2000); Furfine (2003); Iori et al. (2006); Nier et al. (2007). Boissay (2006) and Battiston et al. (2007), instead, focus on the trade-credit relationships along the "supply chain".
} 
connecting firms belonging to different layers of the same industry, the corporate sector) and outside credit (i.e. credit relationships connecting agents belonging to different sectors, i.e. banks and firms). In that paper, however, the network is static, i.e. its structure does not change over time. The specific contribution of the present paper is the introduction of a mechanism for the endogenous evolution of the network structure, the preferred-partner choice rule which is defined as follows. In every period, each customer search for the minimum of the prices charged by a randomly selected set of suppliers; if the minimum price is lower than the price the customer paid to the old supplier in the previous period, he will switch to the new supplier, otherwise he will stick to the old supplier. In the jargon of the network literature, the number of links connecting the nodes of the customers to a certain node of the suppliers changes over time so that the topology of the network is also in a process of continuous evolution. ${ }^{2}$

In the credit network we consider households play the role of passive final consumers. They spend their entire income purchasing consumption goods. The corporate sector consists of two layers of firms. Downstream (D hereafter) firms produce consumption goods, while upstream (U hereafter) firms supply intermediate inputs to D firms. Banks extend credit to firms in both layers. D firms are pure borrowers: they borrow from U firms (trade credit) and from banks (bank loans). Banks are pure lenders: they lend to D and $U$ firms. $U$ firms are borrowers and lenders at the same time: they borrow from banks and lend to D firms.

Lenders conceive the borrower's net worth as a proxy of creditworthiness. Hence credit extended is increasing with the borrowers' net worth. Since the scale of production of D firms is constrained only by the availability of funds, in the end, the supply of consumption goods is increasing with net worth.

The net worth of D firms is the engine of growth and fluctuations in this economy. The scale of activity of $U$ firms, in fact, is determined by the production of $\mathrm{D}$ firms. Changes in the D net worth, therefore, brings about changes in the same direction of $U$ production, profit and net worth. An unexpected shock to D revenues affect the credit relationship between D firms and their U suppliers. Also banks are involved because the interest rate that banks charge, are a function of borrowers' net worth.

If the shock is large enough, the D firm may be unable to fulfill debt commitments and go bankrupt. "Bad debt", i.e. non-performing loans-affect the net worth of lenders, who can react increasing the interest rate. The interest rate hike leads to more bankruptcies and eventually to a bankruptcy chain: "the high rate of bankruptcy is a cause of the high interest rate as much as a consequence of it" (Stiglitz and Greenwald, 2003, p. 145).

The endogenous evolution of credit interlinkages affects the extent of bankruptcies' diffusion, because of the interdependence of firm and bank behaviours: the default of one agent (e.g., a downstream firm) can cause the default of another agent by decreasing

\footnotetext{
2 Jackson (2005) distinguishes between a random graph approach to network formation, borrowed from physics, and the game theoretic approach specifically designed to deal with economic networks. The former is, in a sense, "mechanical": networks formation is purely stochastic or the product of an ad hoc algorithm. The latter focuses on "equilibrium" networks, where links are formed as a consequence of cost-benefit analysis on the part of self-interested individuals. The approach followed in the present paper is half-way between the two: the preferred partner choice rule allocates links to nodes as a consequence of the algorithm that represents the search for the lowest price on the part of customers.
} 
its financial soundness (e.g., an upstream firm linked to the bankrupt downstream one) and so on, depending on the number of links among agents (the default of an agent with many links implies a high probability of bankruptcy diffusion across the network).

All in all, we consider four markets: consumption goods, intermediate goods, labour and credit. "Quantities", i.e. the amount of consumption and intermediate goods produced, labour employed and credit extended are not affected by "prices". They depend, instead, in a complicated way on the financial conditions of the agents involved.

In two of the markets, i.e. the markets for intermediate goods and for bank loans, a preferred partner choice rule is applied. In these cases, the "prices" i.e. the interest rate on trade credit and on bank loans - affect the number of clients of each seller- the $\mathrm{U}$ firms and the banks, respectively-and therefore their profits and net worth. ${ }^{3}$

We study the properties of the network by means of simulations, which show that a business cycle at the macroeconomic level can develop as a consequence of the complex interaction of the agents' financial conditions. In other words, statistical regularities emerge as a self-organised process at the aggregate level. At the same time, the main facts of firms' demography (such as power law distribution of firms' size and Laplace distribution of growth rates) emerge endogenously.

The paper is organized as follows. The model is presented and discussed in Sect. 2. Section 3 is devoted to the discussion of the simulation results. Section 4 concludes.

\section{The model}

We model a multi-sector economy in discrete time $(t=1,2, \ldots, T)$ populated by a multitude of heterogeneous agents. The economy consists of three sectors: a downstream sector consisting of $I$ firms (labeled by the index $i=1,2, \ldots, I$ ), an upstream sector with $J$ firms $(j=1,2, \ldots, J)$ and a banking sector consisting of $Z$ banks $(z=1,2, \ldots, Z)$. In order to keep the analysis simple, the number of firms and of banks is exogenous. 4

There are two goods, a consumption good and an intermediate good. D firms produce a perishable consumption good using labor and intermediate goods. For simplicity and as a first approximation to a more realistic setting, we assume that firms sell all the output they produce at a stochastic price. In other words, households absorb completely the supply of consumption goods. Therefore D firms do not hold inventories-either voluntary or involuntary-of consumption goods.

U firms produce the intermediate good "on demand" with a technology that requires only labor. Therefore U firms do not hold inventories of intermediate goods. We are ruling out by construction the possibility of avalanches of output due to the mismatch of demand and supply of intermediate goods along a supply chain à la (Bak et al. 1993).

The financial side of the economy is characterized by two lending relationships: (i) downstream and upstream firms obtain credit from banks; (ii) downstream firms buy intermediate goods from upstream firms by means of a commercial credit contract.

\footnotetext{
3 On the other markets prices are exogenous, random (in the case of consumption goods) or deterministic (in the case of the labour market).

4 Since in our framework agents can leave the market due to bankruptcy, in order to preserve constancy of the number of agents we have to apply a one-to-one replacement procedure. See below.
} 
The structure of the network of expenditure, production and credit relationships evolves endogenously due to the decentralized interaction among agents, on the basis of a simple incentive mechanism which we have labelled the preferred-partner choice: in every period each D firm looks for the $U$ firm with the lowest price of intermediate goods; at the same time each firm searches for the bank with the lowest interest rate.

The core assumption of the model is that the scale of activity of the $i$ th D firm at time t, i.e. the level of production $Y_{i t}$-is an increasing concave function of its financial robustness, captured by net worth $A_{i t}$ :

$$
Y_{i t}=\phi A_{i t}^{\beta}
$$

where $\phi>1,0<\beta<1$ are parameters, uniform across D firms. The equation above represents the financially constrained output function.

There are (at least) two rationales for (1). First, it can be thought of as a simple rule of thumb in a world in which (i) bounded rationality prevents the elaboration of optimizing decision-making processes and (ii) asymmetric information between borrowers and lenders yields a financing hierarchy in which net worth ranks first.

Alternatively one can think of equation (1) as the solution of an optimization problem on the part of the firm. According to Greenwald and Stiglitz (1993) for instance the problem of the form consists in maximizing expected profits $E\left(\pi_{i}\right)$ net of bankruptcy costs $C_{i}$ weighted by the probability of bankruptcy $\Omega_{i}$. From the definition of profits follows that they are an increasing function of output $Y_{i}$ given net worth $A_{i}$. Bankruptcy costs are assumed to be increasing with the firm's size. Finally, from the definition of the probability of bankruptcy, it turns out that it is increasing with the scale of activity, given net worth. An increase of financial fragility, captured by a reduction of net worth, brings about an increase of the probability of bankruptcy. In the end the Greenwald-Stiglitz characterization of the problem of the firm is:

$$
\max _{Y_{i}} V\left(Y_{i} ; A_{i}\right)=E\left(\pi\left(Y_{i} ; A_{i}\right)\right)-C\left(Y_{i}\right) \Omega\left(Y_{i} ; A_{i}\right)
$$

whose solution is

$$
Y_{i}=\arg \max V\left(Y_{i} ; A_{i}\right)=f\left(A_{i}\right)
$$

with $f^{\prime}>0$. Equation (1) can be considered a linearization of (2). By construction, the second interpretation of (1) is grounded on more stringent requirements of rationality than those implicit in (i) above. However, it is still true that asymmetric information yields a financing hierarchy as assumed in (ii). The concavity of the financially constrained output function captures the idea that an increase in the variance of financial conditions brings about a reduction of average (and therefore aggregate) output.

For simplicity we assume that the production function of D firms is of the Leontief type: $Y_{i}=\min \left(\frac{1}{\delta_{d}} N_{i}, \frac{1}{\gamma} Q_{i}\right)$ with $\delta_{d}>0$ and $\gamma>0$. Therefore, D firms have the following labor and intermediate goods requirement functions: $N_{i t}=\delta_{d} Y_{i t}, Q_{i t}=\gamma Y_{i t}$. In the end, both the demand for labor and the demand for intermediate goods of 
downstream firms depend in a non-linear way on their financial conditions. $N_{i t}=$ $\delta_{d} \phi A_{i t}^{\beta}, Q_{i t}=\gamma \phi A_{i t}^{\beta}$.

Final goods are sold at a stochastic price $u_{i t}$, that is a random variable uniformly distributed in the interval $(0,2) .{ }^{5}$ We can provide the following rationale for this apparently restrictive assumption. Let the demand of the $i$ th commodity in period t be $d\left(u_{i t}, \delta_{i t+1}\right)$ where $u_{i t}$ is the relative price of the $i$ th commodity and $\delta_{i t}$ is a stochastic demand disturbance specific to the market in question. Let supply be $s_{i t}$. By assumption $s_{i t}$ is made up of the quantities produced by a "large number" of producers so that the contribution of each firm to total supply is negligible. In equilibrium $u_{i t}=f\left(\delta_{i t}, s_{i t}\right)$ i.e. the relative price is an increasing function of the demand disturbance, given the predetermined supply. If demand is sufficiently elastic, changes in supply do not affect the relative price significantly so that the relative price is essentially an increasing function of random demand. A high realization of $u_{i t}$ can be thought of as a regime of high demand which drives up the relative price of the commodity in question. In a regime of low demand, the realization of $u_{i t}$ turns out to be low and may push the firm out of the market if it is "too low", i.e. if it makes the net worth of the firm negative.

Upstream firms produce the intermediate good by means of a Leontief technology which employs only labor: $Q_{j t}=\frac{1}{\delta_{u}} N_{j t}$ where $\delta_{u}>0$. For simplicity, we assume an asymmetric structure of the D-U network: many D firms can be linked to a single $\mathrm{U}$ firm but each D firm has only one supplier of intermediate goods.

In each period the supplier-say the $j$ th firm-receives orders from a set of D customers which will be denoted by $\Phi_{j}$. Since each D firm looks for the U firm with the lowest price of intermediate goods, by construction the number of elements of $\Phi_{j}$ depends on the price $p_{j t}$ that the upstream firm charges to its customers: the lower the price, the higher the number of downstream firms placing orders to the $j$ th supplier of intermediate goods.

The price the supplier is charging is defined as $p_{j t}=1+r_{j t}$ where $r_{j t}$ is the interest rate on trade credit. We assume that the level of $r_{j t}$ depends on the financial condition of the upstream firm:

$$
r_{j t}=\alpha A_{j t}^{-\alpha}
$$

with $\alpha>0$. In words, the interest rate on commercial paper charged to each and every D firm belonging to $\Phi_{j}$ is decreasing with the financial soundness of the U firm. If the $U$ firm is in good shape from the financial point of view, it will be eager to extend trade credit at more favourable terms to its D customers.

In principle, the interest rate on trade credit charged by the $j$ th $U$ firm should be affected also by the financial conditions of the borrowers, i.e. of the D firms in the set

\footnotetext{
5 Following Greenwald and Stiglitz (1993) (GS hereafter) we assume that firms sell all the output they produce at a stochastic price. Undoubtedly, this is the source of an important idiosyncratic shock at the firm-level which influences the whole economy due to a direct mechanism - via output volatility of downstream firms - and an indirect mechanism, i.e. the propagation of shocks through productive and credit interlinkages. In our framework, as in GS, stochastic prices are the vehicle of idiosyncratic shocks at the firm level. In our setting, however, the mechanism of propagation and amplification is richer than in GS because shocks affecting downstream firms spread to connected agents in a networked-economy with bank and trade credit.
} 
$\Phi_{j}$. In order to keep the framework as simple as possible, however, we have assumed that asymmetric information prevents a correct assessment of the financial conditions of the borrowers on the part of the lenders. Therefore the interest rate on trade credit incorporates only the financial condition of the lender.

We can propose the following rationale for this assumption. In our framework, the existence of trade credit is basically due to a transaction motive (Nilsen 2002). Firms aim at extending market shares (when agents' financial conditions allow to act in this way). The increase of upstreams' net worth produces a decrease of interest rates on trade credit affecting aggregate credit conditions in a way similar to that characterizing banks. In a sense, upstream firms use trade credit as a marketing strategy (Summers and Wilson 2001). Like expenditures in advertising, commercial credit is an investment that, by establishing a long-term relationship between the lender and the borrower, yields a long term return (Nadiri 1969). In our setting, firms extend trade credit at more favourable terms, increasing the likelihood of gaining new customers, when their financial conditions are sound. Accordingly, our modelling choice is consistent with an explanation based on trade credit as a 'long-term investment' aimed at achieving new customers through applying more favourable commercial credit conditions. ${ }^{6}$

While the scale of production of D firms is financially constrained, i.e. it is determined by their degree of financial robustness - the scale of production of $U$ firms is demand constrained, i.e. it is determined by the demand of intermediate goods on the part of D firms. Therefore, the financial conditions of the D firms are the driving force also for the production of $U$ firms. The more robust, on average, D firms, the higher their scale of activity and the demand for labour and intermediate goods so that the higher will be, on average, the scale of activity of $U$ firms. For instance, the demand of intermediate goods - and therefore the scale of production - of the $j$ th $U$ firm will be $Q_{j t}=\gamma \sum_{i \in \Phi_{j}} Y_{i t}=\gamma \phi \sum_{i \in \Phi_{j}} A_{i t}^{\beta}$ and the demand for labor will be $N_{j t}=\delta_{u} \gamma \phi \sum_{i \in \Phi_{j}} A_{i t}^{\beta}$.

Firms face a financing hierarchy in which internal finance ranks first and bank loans second. Therefore, by assumption, the financing gap, i.e. the difference between the firm's expenditures and internal finance, is filled by means of credit. For U firms, the financing gap is the difference between the wage bill and net worth. As to D firms, expenditures consists of wages and the cost of intermediate goods. In order to keep the analysis as simple as possible, however, we assume that also for D firms the financing gap is the difference between the wage bill and net worth. This means that the acquisition of intermediate goods can be financed by means of trade credit, not by bank loans.

Accordingly, the demand of credit is equal to $B_{x t}=W_{x t}-A_{x t}$ where $W_{x t}=w N_{x t}$ is the firm's wage bill ( $x=i$ for $\mathrm{D}$ firms, $j$ for $\mathrm{U}$ firms). We assume that the real

\footnotetext{
6 According to Mateut and Mizen (2003), firms behaves like banks in extending credit to other firms, charging to borrowers an external finance premium due to collection costs, e.g. costly state verification (Boissay 2006). In this way, trade credit affects aggregate credit conditions in the economy. Mateut (2001) shows that trade credit has an important role in the transmission of monetary policy, interacting with external financing decision made by banks. There is then a finance motive underlying commercial credit (Nilsen 2002). Nevertheless, in our model, trade credit is not a substitute for bank credit: we do not model the interplay between bank and trade credit (although this is a relevant aspect highlighted by the literature: see, for instance, Gertler and Gilchrist (1993), on commercial credit, and Jaffee and Stiglitz (1990), on the interplay between commercial credit and credit rationing).
} 
wage $w$ is constant and uniform across firms. By assumption, labour is abundant so that firms do not face any labour shortage at the pre-determined real wage.

Self-financed firms, i.e. firms with a level of net worth sufficient to finance the wage bill, do not demand credit. From the expression above follows that the demand for credit of the $i$ th $\mathrm{D}$ firm is

$$
B_{i t}=w N_{i t}-A_{i t}=w \delta_{d} \phi A_{i t}^{\beta}-A_{i t}
$$

so that a D firm is self financed if it has net worth $A_{i t} \geq \hat{A} \equiv\left(w \delta_{d} \phi\right)^{\frac{1}{1-\beta}}$.

As to $U$ firms, the demand for credit of the $j$ th $U$ firm is

$$
B_{j t}=w N_{j t}-A_{j t}=w \delta_{u} \gamma \phi \sum_{i \in \Phi_{j}} A_{i t}^{\beta}-A_{j t}
$$

so that a $\mathrm{U}$ firm is self financed if it has net worth $A_{j t} \geq \hat{A}_{j} \equiv w \delta_{u} \gamma \phi \sum_{i \in \Phi_{j}} A_{i t}^{\beta}$. The higher the net worth of $D$ customers of the $\mathrm{U}$ firm, the less likely it is that the $\mathrm{U}$ firm is self financed.

For simplicity, we assume an asymmetric structure of the firms-banks network: many firms can be linked to a single bank but each firm has only one supplier of loans. The set of customers of the $z$ th bank will be denoted by $\Phi_{z}$. We assume that each bank has a certain degree of market power. Since each firm looks for the bank with the lowest interest rate, by construction the number of elements of $\Phi_{z}$ depends on the interest rate the bank charges to its customers: the lower the interest rate, the higher the number of firms asking loans to the $z$ th bank.

The $z$ th bank adopts the following rule in setting the interest rate on loans to the $x$ th borrower ( $x=i$ for downstream, $j$ for upstream):

$$
r_{z t}^{x}=\sigma A_{z t}^{-\sigma}+\theta\left(l_{x t}\right)^{\theta}
$$

where $A_{z t}$ is the net worth of the $z$ th bank and $l_{x t}=B_{x t} / A_{x t}$ is the leverage ratio of the $x$ th firm, $\sigma$ and $\theta$ positive parameters. Accordingly, the interest rate on bank loans is (i) decreasing with the financial soundness of the bank (proxied by the bank's net worth $A_{z t}$ ) and (ii) increasing with the firms' leverage ratio.

The rationale of (i) is obvious: if the bank is in good shape from the financial point of view, it will be eager to extend credit at more favourable terms. This is the case, for instance, if the bank adopts a rule of thumb according to which the amount of loans outstanding must be reduced if it is "too high" with respect to the bank's own capital, i.e. net worth. ${ }^{7}$ When net worth is "too low", the bank pushes the interest rate up to reduce the number of borrowers the demand for loans.

$\overline{7}$ Total loans extended by the $z$ th bank are

$$
B_{t}^{z}=\sum_{i \in \Phi_{z}} B_{i t}+\sum_{j \in \Phi_{z}} B_{j t}=\sum_{i \in \Phi_{z}}\left(w \delta_{d} \phi A_{i t}^{\beta}-A_{i t}\right)+\sum_{j \in \Phi_{z}}\left(w \delta_{u} \gamma \phi \sum_{i \in \Phi_{j}} A_{i t}^{\beta}-A_{j t}\right)
$$

If the interest rate goes down more borrowers will be attracted by the bank and more loans will be extended. 
As to (ii), we simply assume that the firm penalizes financially fragile firms. In a sense, we adopt the principle according to which the interest rate charged by the lender incorporates an external finance premium increasing with leverage and therefore inversely related to the borrower's net worth. ${ }^{8}$

Notice that the leverage ratio of the $i$ th $\mathrm{D}$ firm is

$$
l_{i t}=B_{i t} / A_{i t}=w \delta_{d} \frac{Y_{i t}}{A_{i t}}=w \delta_{d} \phi A_{i t}^{-(1-\beta)}-1
$$

i.e., it is decreasing with net worth. Therefore, in the end, the interest rate charged by the $z$ th bank to the $i$ th $\mathrm{D}$ firm will be:

$$
r_{z t}^{i}=\sigma A_{z t}^{-\sigma}+\theta\left(w \delta_{d} \phi A_{i t}^{-(1-\beta)}-1\right)^{\theta}
$$

i.e., it will be a decreasing function of the net worth of the bank and of the firm.

The situation is different in the case of $U$ firms. The leverage is

$$
l_{j t}=B_{j t} / A_{j t}=w \delta_{u} \frac{Q_{j t}}{A_{j t}}-1=\frac{w \delta_{u} \gamma \phi}{A_{j t}} \sum_{i \in \Phi_{j}} A_{i t}^{\beta}-1
$$

since $Q_{j t}=\gamma \phi \sum_{i \in \Phi_{j}} A_{i t}^{\beta}$ as shown above. The leverage of the $\mathrm{U}$ firm is decreasing with its own net worth but increasing with the net worth of the downstream customers. The interest rate charged by the $z$ th bank to the $j$ th $\mathrm{U}$ firm will be:

$$
r_{z t}^{j}=\sigma A_{z t}^{-\sigma}+\theta\left(\frac{w \delta_{u} \gamma \phi}{A_{j t}} \sum_{i \in \Phi_{j}} A_{i t}^{\beta}-1\right)^{\theta}
$$

i.e. it will be a decreasing function of the net worth of the bank and of the j-firm but an increasing function of the net worth of the downstream customers.

Each D firm has a (productive and credit) relationship with an U firm. Initially, i.e. at time $t=1$, the network of firms is random, i.e. the links among $\mathrm{D}$ and $\mathrm{U}$ firms are established at random. Therefore, for instance the $\mathrm{D}$ firm indexed by $i$ ( $D i$ ) ends up linked to the $\mathrm{U}$ firm indexed by $j_{0}\left(U j_{0}\right)$. In each of the subsequent periods, the network changes endogenously according to a preferred-partner choice rule (with noise) which is defined as follows:

- with (a small) probability $\varepsilon$ the D firm chooses a partner (i.e. a U supplier) at random;

- with probability $1-\varepsilon$ he looks at the prices of a randomly selected number-say $M-$ of U firms;

\footnotetext{
8 In a sense in our model the bank behaves as a lender in a Bernanke and Gertler $(1989,1990)$ world characterized by asimmetric information and costly state verification. See Bernanke et al. (1999) for a comprehensive exposition of the approach.
} 
- if the minimum observed price — say the price of $U j_{1}$ - is lower than the price of $U j_{0}$, then $D i$ will switch to $U j_{1}$;

- otherwise, $D i$ will stick to $U j_{0}$.

In the jargon of the network literature, the number of links connecting D nodes to a certain $U$ node changes over time due to the changing price charged by the $U$ firm so that the topology of the network is also in a process of continuous evolution. The total number of nodes, however, is constant.

The preferred-partner choice rule applies also to the relationship between firms (both $\mathrm{D}$ and $\mathrm{U}$ ) and banks. At time $t=1$ the links among firms and banks are established at random. For instance, firm $D i$ ends up linked to the bank $z_{0}\left(B z_{0}\right)$. Afterwards, with probability $1-\varepsilon$ each firm looks at the interest rate charged by a randomly selected number-say $N$-of banks. If the minimum observed interest rate- say the one charged by $B z_{1}$-is lower than the one charged by $B z_{0}$, then $D i$ will switch to $B z_{1}$; otherwise, he will stick to $B z_{0}$.

Suppose that $D i$ belonging to $\Phi j_{0}$ goes bankrupt. The demand of intermediate goods produced by $U j_{0}$ goes down and so do revenues, profits and net worth. The interest rate $r_{z t}^{j_{0}}=\sigma A_{z t}^{-\sigma}+\theta\left(l_{j_{0} t}\right)^{\theta}$ goes up. Therefore also $U j_{0}$ can go bankrupt. In principle there can be negative repercussions also on other $\mathrm{D}$ firms belonging to $\Phi j_{0}$ which cannot produce as much as they want, due to the bankruptcy of their supplier $U j_{0}$. An avalanche of bankruptcies will follow due to the positive feedback of the bankruptcy of a single agent on the net worth of the "neighbours", linked to the bankrupt agent by trade or credit links. Notice, however, that there is also a negative feedback with a stabilizing effect due to the fact that the smaller net worth of the part of D firms makes the leverage of U firms smaller and therefore it makes the interest rate charged by the bank smaller.

The profit of the $i$ th D firm is defined as follows: $\pi_{i t}=u_{i t} Y_{i t}-\left(1+r_{z t}^{i}\right) B_{i t}-$ $\left(1+r_{j t}\right) Q_{i t}$ where $u_{i t}$ is the price and $Y_{i t}$ is the quantity of consumption goods, $r_{z t}^{i}$ is the interest rate charged by $B z$ to $D i, r_{j t}$ is the interest rate on trade credit charged by $U j$ to $D i$ and $Q_{i t}$ is the amount of intermediate input that $D i$ has bought from $U j$. Upstream firms' profit is equal to: $\pi_{j t}=\left(1+r_{j t}\right) Q_{j t}-\left(1+r_{z t}^{j}\right) B_{j t}$. Banks' profit is equal to $\pi_{z t}=\sum_{i \in I_{z}}\left(1+r_{z t}^{i}\right) B_{i t}+\sum_{j \in J_{z}}\left(1+r_{z t}^{j}\right) B_{j t}$, where $I_{z}$ and $J_{z}$ are, respectively, the set of $\mathrm{D}$ and $\mathrm{U}$ firms interacting with bank z. ${ }^{9}$

At the end of the period, the net worth of the $x$ th agent ( $x=i$ for downstream, $j$ for upstream, $z$ for bank) is defined as follows

$$
A_{x t+1}=A_{x t}+\pi_{x t}-B D_{x t}
$$

where $B D_{x t}$ is "bad debt". In fact, if a borrower cannot pay back the loan obtained from the lender and goes bankrupt, the lender has a "bad debt" (non-performing loan), that is accounted for as a reduction of its net worth. The agent goes bankrupt if $A_{x t+1} \leq 0$.

In our framework, the lenders are the $\mathrm{U}$ firms and the banks, while both types of firms can be borrowers (if they are not self-financed).

${ }^{9}$ Of course $I_{z} \cup J_{z}=\Phi_{z}$. 
In the case of U firms, "bad debt" is $B D_{j t}=\left(1+r_{j t}\right) \gamma \sum_{i \in \Phi_{j}^{B}} Y_{i t}$, i.e. the amount of trade credit not reimbursed (intermediate goods not paid for) by bankrupt D customers, which are grouped for convenience in the set $\Phi_{j}^{B}$.

In the case of banks, "bad debt" is $B D_{z}=\sum_{i \in \Phi_{z}^{B}}\left(1+r_{z t}^{i}\right) B_{i t}+\sum_{j \in \Phi_{z}^{B}}\left(1+r_{z t}^{j}\right) B_{j t}$ i.e. non-performing loans of bankrupt $\mathrm{D}$ and $\mathrm{U}$ firms, which are grouped for convenience in the set $\Phi_{z}^{B}$.

\section{Simulation results}

In this section, we analyze the dynamic properties of the credit network modelled above, with a particular emphasis on the amplitude and length of bankruptcy avalanches. We perform computer simulations of an economy consisting of $I=500 \mathrm{D}$ firms, $J=250 \mathrm{U}$ firms and $Z=100$ banks over a time span of $T=1,000$ periods. There are 12 parameters in the model, which are set as follows: $\phi=1.2, \beta=0.8$, $\delta_{d}=0.5, \delta_{u}=1, \gamma=0.5, \alpha=0.1, \sigma=0.1, \theta=0.05, w=1, M=5, N=5$, $\varepsilon=0.01$.

The net worth of agents (firms and banks) at the beginning of the time span $(t=1)$ is set to 1 . We assume a simple mechanism of entry-exit: bankrupt firms/banks are replaced with new entrants on the basis of a one-to-one replacement. New agents are endowed with an initial amount of net worth drawn from a uniform distribution with mean 1 and finite variance. ${ }^{10}$

Figure 1 shows some relevant aspects emerging from the simulation of the credit network. Panel (a) shows the fluctuating behavior of the D aggregate production. The $\mathrm{U}$ aggregate production follows the same dynamic pattern since $\mathrm{U}$ suppliers produce intermediate goods for D production "on demand". Panel (b) shows that, over time, a power law distribution of firms' size emerges, according to the empirical evidence on firm size distribution (Axtell 2001; Gaffeo et al. 2003). Accordingly, starting from identical initial conditions, firms become rapidly heterogeneous ${ }^{11}$ In addition, the distribution of the number of links for each lender ( $U$ firm or bank) becomes asymmetric over time due to the preferred-partner choice rule governing the interaction among borrowers and lenders. In other words, the actual degree distribution of the credit network suggests that some lenders, in the right tail of the distribution, have a number of customers higher than that generated by a normal distribution. This holds true for the number of commercial credit relationships between $\mathrm{D}$ and $\mathrm{U}$ firms (panel (c)), as well as for the number of connections between firms and banks (panel (d)).

The length of credit relationships is endogenously determined by the preferredpartner choice rule. In particular, the average length of the D-U link across 100 Monte Carlo simulations of the model is equal to 1.4; in the case of the D-B link the

\footnotetext{
10 For the sake of simplicity, the total number of agents in the economy is constant over time. In order to avoid capital coutercyclicality, when new agents replace bankrupt ones, the initial endowment of capital for entrants is "small" with respect to other agents or the average net worth.

11 Each D firms is hit by a price shock in each time period because the sale price is stochastic. Therefore the accumulation of net worth on the part of each D firm rapidly takes different routes. The accumulation of net worth on the part of $\mathrm{U}$ firms and banks is determined as a consequence.
} 

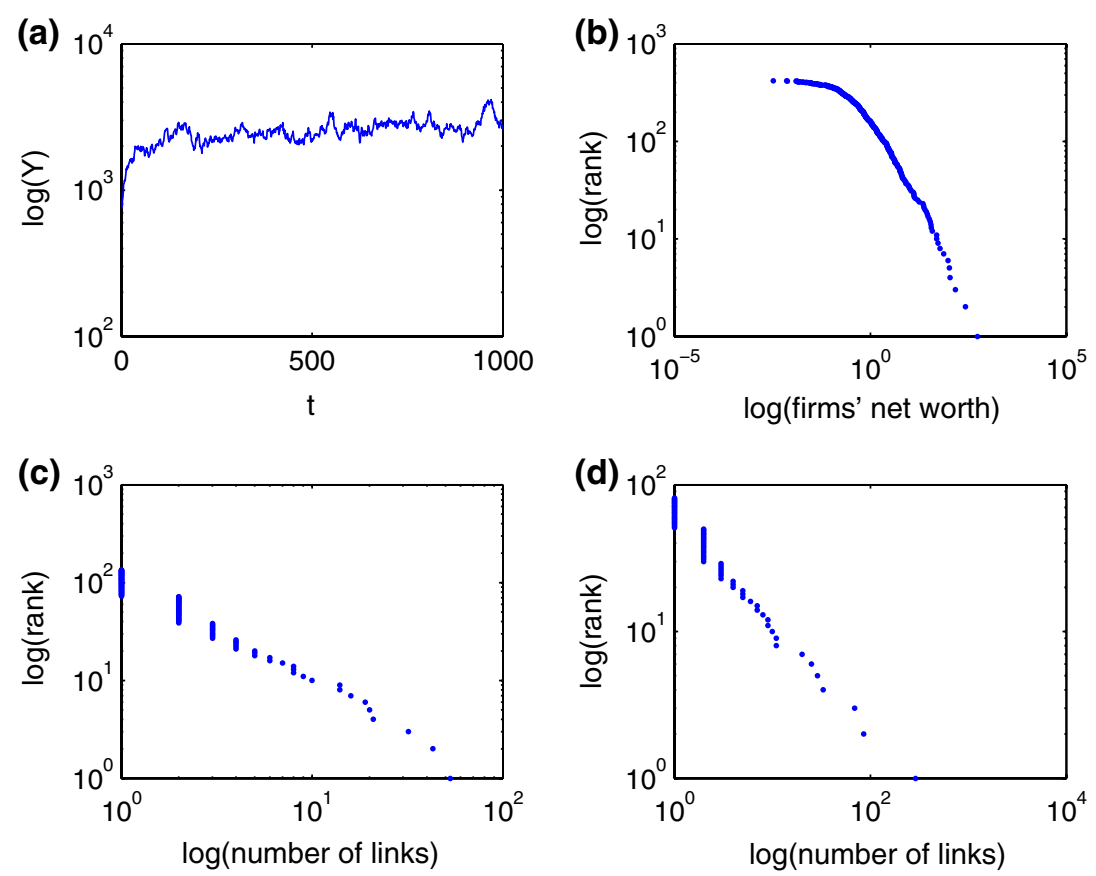

Fig. 1 a Aggregate production of downstream firms. b Firm size distribution (in terms of net worth). c Degree distribution of the network: downstream versus upstream firms. d Degree distribution of the network: firms versus banks

average length is equal to 4.7; instead, the average length of the U-B link is equal to 18.9. The higher stability of relationships depends on the different bankruptcy rate characterizing different agents, decreasing from D to U and B sectors.

Lenders with a high number of links are less vulnerable to bankruptcy because they are also financially sound and can supply credit at better conditions. Financially sound U firms set lower prices than financially fragile ones, attract more D firms, are more profitable and further increase their financial robustness. The opposite is true for financially fragile $U$ firms. The corporate $U$ sector becomes polarized and the degree distribution becomes asymmetric. A positive feedback occurs.

In a similar way, financially sound banks set lower prices than financially fragile ones, attract more firms, are more profitable and further increase their financial robustness. The opposite is true for financially fragile banks. The banking sector becomes polarized and the degree distribution becomes asymmetric.

All in all, the attachment operating through the choice of partners by lower prices and interest rates increases the number of links of financially sound firms and banks (in this way they can offer lower prices and interest rates also in the following periods) that improve their financial positions, increasing the "robustness" of the network. On the other hand, the evolution of a scale invariant degree distribution increases also the "vulnerability" of the network because the default of a highly connected agent can have serious consequences on the stability of the networks generating an avalanche of bankruptcies. 
Fig. 2 Bankruptcy diffusion mechanism

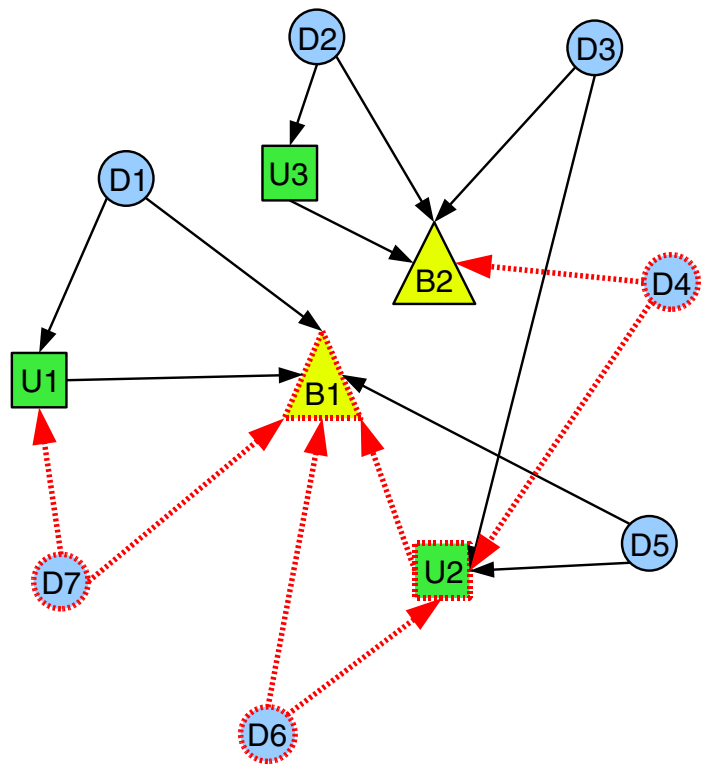

The default of an agent can generate a diffusion of bankruptcies across the network. Figure 2 provides a simple graphical representation of what can happen in the credit network economy as a consequence of the default of one or more firms. Consider a small part of the network involving downstream firms from $D 1$ to $D 7$, upstream firms $U 1, U 2$ and $U 3$, and banks $B 1$ and $B 2$. Suppose that, for instance, downstream firms D4, D6 and D7 go bankrupt due to idiosyncratic (price) shocks. These firms do not fulfill debt commitments. As a consequence, the financial conditions of lenders deteriorate due to bad loans. In the case described in Fig. 2, U2 and B1 go bankrupt, while U1 and B2 survive to the failure of their partners. Accordingly, the channel of bankruptcy propagation is the following: the failure of D4 and D6 provokes the default of U2; the failure of D6, D7 and U2 provokes the default of B1. Although U1 and B2 survive to their partners' default, the deterioration of their financial conditions, due to bad loans incidence on balance sheets, produce an increase of the interest rate (charged on their old and new partners) increasing the likelihood of additional failures. As a result, our model demonstrates that "the high rate of bankruptcy is a cause of the high interest rate as much as a consequence of it" (Stiglitz and Greenwald, 2003, p. 145).

The seriousness of agents' defaults with respect to bankruptcy avalanches and business fluctuations depends on the size of agents and their connectivity. In fact, even a high number of bankruptcies can be absorbed by the system without generating a domino effect. Accordingly, the extent of bankruptcy events depends also on the amount of bad debts.

Figure 3 displays the time evolution of the aggregate bad debt: it emerges that it is more likely to observe "large" amounts of bad debt in sequence. This is in line with the above description of the bankruptcy diffusion mechanism: agents' failures provoke financial distress with a deterioration of credit conditions, due to the increase 


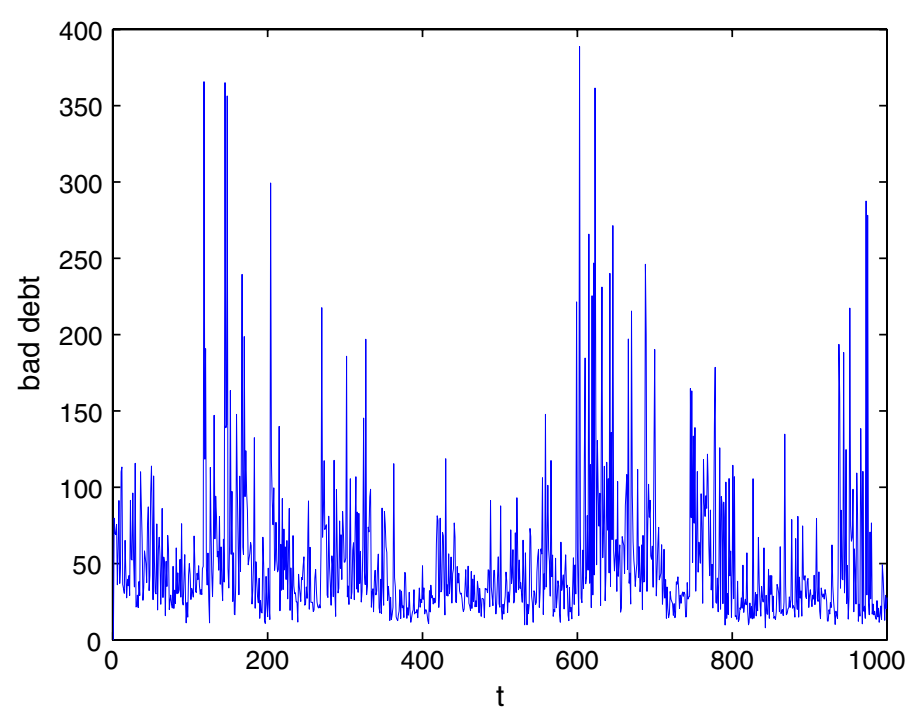

Fig. 3 Aggregate bad debt: time evolution

of interest rates, producing additional failures and large amounts of bad debt, until the return of "normal conditions" in the credit network economy.

In order to examine the incidence of extreme events on the credit network evolution, we compute the variable $B D^{\prime}$, that is the absolute value of the difference between aggregate bad debt and its median. After that, we calculate the probability of observing values of $B D^{\prime}$ larger than $x \sigma_{B D}$, where $\sigma_{B D}$ is the standard deviation of aggregate bad debt and $x$ is a positive parameter. Figure 4 shows that extreme events, with a "high" value of $x$, have a positive, even if "low", probability of realization.

Another relevant aspect is the length of bankruptcy chains. In order to examine this aspect, we calculate the number of periods characterized by "large" amount of bad debt: in particular, for each period we control if $B D^{\prime}$ is larger than $2 \sigma_{B D}$. The credit network economy under scrutiny verifies this conditions in 52 periods. We also compute the realization of a random process with the same average probability $(52 / 1,000)$ of verifying the conditions $B D^{\prime}>2 \sigma_{B D}$. Figure 5 clearly shows that the credit network economy is characterized by the clustering of "large bad debt" events, according to which said above, a feature not displayed by a random process.

Finally, the occurrence of bankruptcy crises amplifies business fluctuations and, as a consequence, the distribution of aggregate growth rates is far from being Gaussian, showing instead a double exponential behavior (Bottazzi and Secchi 2003; Stanley et al. 1996) with a noticeable asymmetry for negative events (see Fig. 6).

\section{Concluding remarks}

We have analyzed the properties of a credit-network economy characterized by inside credit (i.e. credit relationships connecting agents belonging to different groups of 


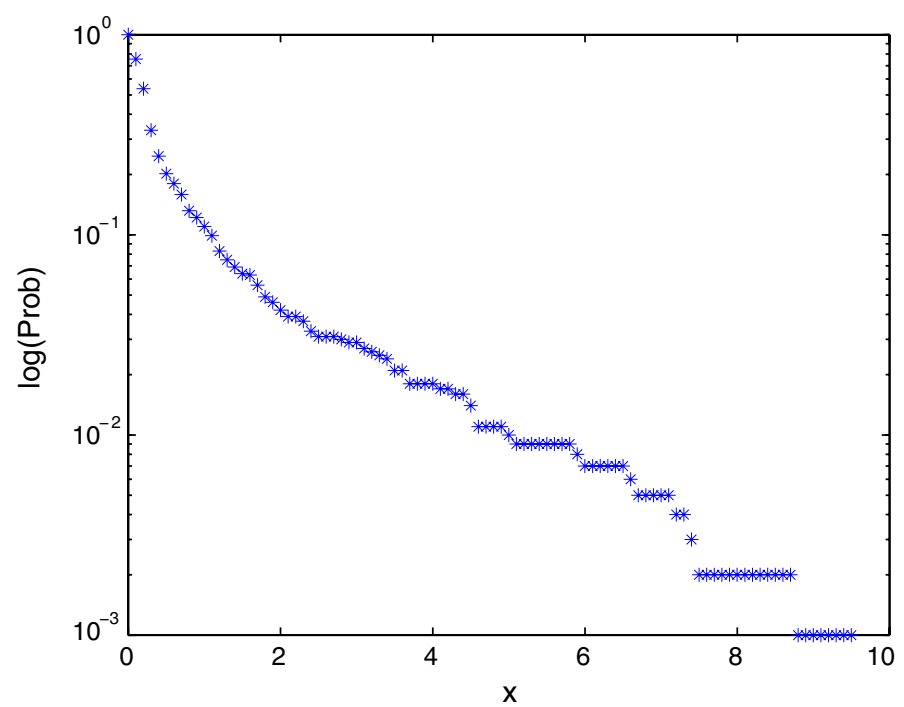

Fig. 4 Aggregate bad debt: probability of extreme events

Fig. 5 Clustering of bankruptcy avalanches

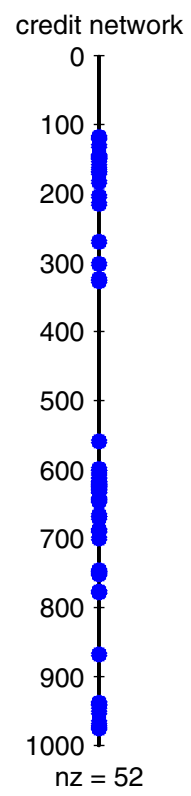

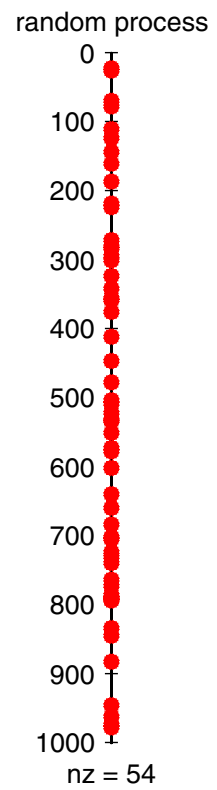

the same sector, i.e. D firms and U firms) and outside credit (i.e. credit relationships connecting agents belonging to different sectors, i.e. firms and banks).

The configuration of productive and credit interlinkages changes over time due to the preferred-partner choice rule, which implies that endogenous changes of the interest rate on trade credit and on bank loans affect the number of clients of each $\mathrm{U}$ firm and each bank. This rule is reminiscent of the preferential attachment rule 


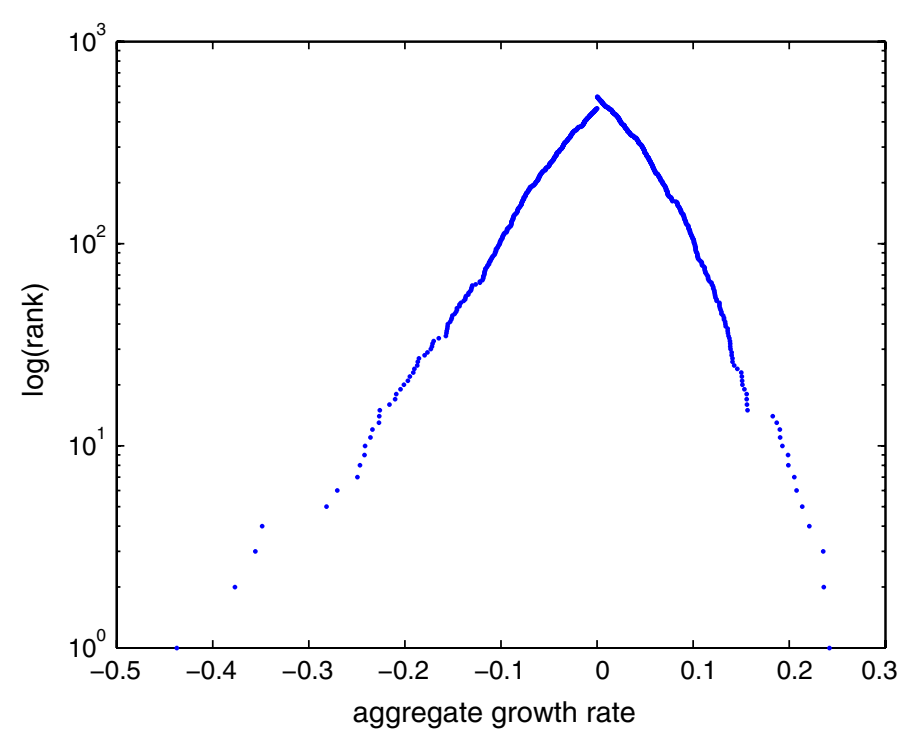

Fig. 6 The distribution of aggregate growth rates

(Barabàsi and Albert 1999) and it is based on a mechanism similar to the fitness model (Bianconi and Barabàsi 2001) already adopted in the network literature. The changing topology of the network affects the propagation of bankruptcies and the shape of business fluctuations.

The borrower's net worth is a proxy of creditworthiness. Hence credit extended is increasing with the borrowers' net worth. Since D output-which consists of consumption goods - is constrained only by the availability of funds, in the end, the supply of consumption goods is increasing with $\mathrm{D}$ net worth. The net worth of D firms turns out to be the driver of growth and fluctuations. U production, in fact, is determined by demand of intermediate inputs on the part of D firms. Changes in the D net worth, therefore, yield changes in the same direction of U production. Also banks are involved because the interest rate that a bank charges is a function of borrowers' net worth.

If a D firm goes bankrupt, not only the supply chain can be disrupted-involving U firms - but also an interest rate hike can follow due to the change in attitude of lenders. More bankruptcies will follow in a bankruptcy avalanche.

The output of simulations shows that a business cycle at the macroeconomic level can develop as a consequence of the complex interaction of the financial conditions of the agents involved. We can also reproduce the main facts of firms' demography: power law distribution of firms' size and Laplace ditribution of growth rates. The preferred choice rule affects essentially the skewness of the firms'size distribution and of the degree distribution of the network.

There are obvious restrictions on the conditions determining the model environment which we plan to relax in the future. An interesting extension is the introduction of an interbank market, which will allow modelling the central bank and monetary policy. In addition, we would like to extend the preferred choice rule also to the goods and 
labour markets. This will imply a more sophisticated design of households' behaviour, which so far has been essentially passive. Our aim is then to further investigate the interplay between the formation of credit interlinkages and macroeconomic dynamics by extending our model in different directions, towards a "complete" credit network.

Acknowledgments We are grateful for insightful comments and criticisms to participants to the Eastern Economic Association meeting, New York City, February 2007—in particular Duncan Foley, whose detailed comments have been expecially useful-, the Net-Work-shop at Catholic University in Milan, April 2007, the XLVIII Annual Meeting of the Italian Economists Society in Turin, October 2007. Last but not least, thanks to the participants to the ESHIA/WEHIA 2008, Warsaw, June 19-21, and, in particular, to Pedro Campos and Paul Ormerod for very useful suggestions. We are grateful to the referees for their insightful comments and criticisms.

\section{References}

Allen F, Gale D (2000) Financial contagion. J Polit Econ 108:1-33

Axtell R (2001) Zipf distribution of U.S. firm sizes. Science 293:1818-1820

Bak P, Chen K, Scheinkman J, Woodford M (1993) Aggregate fluctuations from independent sectoral shocks: Self-organized criticality in a model of production and inventory dynamics. Ricerche Economiche 47(1):3-30

Barabàsi A-L, Albert R (1999) Emergence of scaling in random networks. Nature 286:509-512

Battiston S, Delli Gatti D, Gallegati M, Greenwald B, Stiglitz J (2007) Credit chains and bankruptcy avalanches in supply networks. J Econ Dyn Control 31(6):2061-2084

Bernanke B, Gertler M (1989) Agency costs, net worth and business fluctuations. Am Econ Rev 79:14-31

Bernanke B, Gertler M (1990) Financial fragility and economic performance. Q J Econ 105:87-114

Bernanke B, Gertler M, Gilchrist S (1999) The financial accelerator in quantitative business cycle framework. In: Taylor J, Woodford M (eds) Handbook of macroeconomics, vol 1C. North-Holland, Amsterdam

Bianconi G, Barabàsi A-L (2001) Competition and multiscaling in evolving networks. Europhys Lett 54(4):436-442

Boissay F (2006) Credit chains and the propagation of financial distress. ECB Working Paper No. 573

Bottazzi G, Secchi A (2003) Why are distributions of firm growth rates tent-shaped? Econ Lett 80:415-420

Delli Gatti D, Gallegati M, Greenwald B, Russo A, Stiglitz J (2006) Business fluctuations in a credit-network economy. Phys A 370:68-74

Freixas X, Parigi B, Rochet J (2000) Systemic risk, interbank relations and liquidity provision. J Money Credit Bank 32:611-638

Furfine C (2003) Interbank exposures: quantifying the risk of contagion. J Money Credit Bank 35(1):111128

Gaffeo E, Gallegati M, Palestrini A (2003) On the size distribution of firms: additional evidence from the G7 countries. Phys A 324:117-123

Gertler M, Gilchrist S (1993) The role of credit market imperfections in the monetary transmission mechanism. Scand J Econ 95(1):43-64

Goyal S (2007) Connections. Princeton University Press, New Jersey

Greenwald B, Stiglitz J (1993) Financial market imperfections and business cycles. Q J Econ 108:77-114

Iori G, Jafarey S, Padilla F (2006) Systemic risk on the interbank market. J Econ Behav Organ 61(4):525540

Jackson M (2005) The economics of social networks. In: Blundell R, Newey W, Persson T (eds) Proceedings of the ninth world congress of the Econometric Society. Cambridge University Press, London

Jackson M (2008) Social and economic Networks. Princeton University Press, New Jersey

Jaffee D, Stiglitz JE (1990) Credit rationing. In: Friedman BM, Hahn FH (eds) Handbook of monetary economics, edn 1, vol 2, chap 16. North-Holland, Amsterdam, pp 837-888

Mateut S (2001) Trade credit and monetary policy transmission. J Econ Surv 19(4):655-670

Mateut S, Mizen P (2003) Trade credit and bank lending: An investigation in the determinants of UK manufacturing firms access to trade credit. Working Paper No. 2003/3. European University Institute 
Nadiri MI (1969) The determinants of trade credit in the US total manufacturing sector. Econometrica 37(3):408-423

Nier E, Yang J, Yorulmazer T, Alentorn A (2007) Network models and financial stability. J Econ Dyn Control 31:2033-2060

Nilsen J (2002) Trade credit and the bank lending channel. J Money Credit Bank 34:227-253

Stanley M, Amaral L, Buldyrev S, Havlin S, Leschorn H, Maas P, Salinger M, Stanley E (1996) Scaling behavior in the growth of companies. Nature 379:804-806

Stiglitz J, Greenwald G (2003) Towards a new paradigm in monetary economics. Cambridge University Press, London

Summers B, Wilson N (2001) Trade credit and customer relationships. University of Leeds, Credit Management Research Center, Mimeo

Vega-Redondo F (2007) Complex social networks. Econometric society monograph series. Cambridge University Press, London 